Artigo Original

\title{
Experiência do irmão sadio em relação à doença e hospitalização do irmão com câncer*
}

\author{
Experience of a healthy brother in relation to the disease and hospitalization of his brother with \\ cancer \\ Experiencia del hermano saludable en relación a la enfermedad y hospitalización del hermano con \\ cáncer
}

\author{
Maria de Fátima de Lima Cheron', Myriam Aparecida Mandetta Pettengill ${ }^{2}$
}

\section{RESUMO}

Objetivo: Compreender o significado da experiência de ter um irmão com câncer na perspectiva do irmão sadio. Métodos: Pesquisa descritiva de abordagem qualitativa. Foram realizadas entrevistas semiestruturadas com cinco irmãos de crianças com câncer assistidas em instituição filantrópica localizada no Município de São Paulo. Resultados: O tema central tornando-se amadurecido com o sofrimento permitiu revelar que o irmão sadio torna-se amadurecido em razão do sofrimento que lhe é imposto no decorrer dos acontecimentos. Passa a valorizar a convivência familiar e os pequenos atos do cotidiano que lhe eram despercebidos. Conclusão: A equipe de saúde precisa reconhecer a experiência do irmão e inclú́-lo no cuidado prestado em todas as fases da doença.

Descritores: Criança; Neoplasias/psicologia; Irmãos/psicologia; Relações entre irmãos; Rejeição(Psicologia)

\begin{abstract}
Objective: To understand the meaning of the experience of having a sibling with cancer from the perspective of healthy brother. Methods: A descriptive qualitative research approach. Semi-structured interviews were conducted with five siblings of children with cancer who were receiving care in a philanthropic institution located in São Paulo. Results: The central theme that emerged was suffering as it was revealed that the healthy brother became mature because of the suffering that is imposed in the course of events. They valued family and small acts of daily life that are often undetected. Conclusion: The health care team must recognize the experience of the brother and include it in the care provided at all stages of the disease.
\end{abstract}

Keywords: Child; Neoplasms/psychology; Siblings/psychology; Sibling relations; Rejection (Psychology)

\section{RESUMEN}

Objetivo: Comprender el significado de la experiencia de tener un hermano con cáncer en la perspectiva del hermano saludable. Métodos: Investigación descriptiva de abordaje cualitativo. Fueron realizadas entrevistas semiestructuradas con cinco hermanos de niños con cáncer asistidos en una institución filantrópica localizada en el Municipio de Sao Paulo. Resultados: El tema central tornándose maduro con el sufrimiento permitió revelar que el hermano saludable madura en razón del sufrimiento que le es impuesto en el transcurso de los acontecimientos. Pasa a valorizar la convivencia familiar y los pequeños actos del cotidiano que le eran desapercibidos. Conclusión: El equipo de salud necesita reconocer la experiencia del hermano e incluirlo en el cuidado prestado en todas las fases de la enfermedad.

Descriptores: Niños; Neoplasias/psicología; Hermanos/psicología; Relaciones entre hermanos; Rechazo (Psicología)

* Trabalho de Conclusão de Curso de Enfermagem, Universidade Federal de São Paulo - UNIFESP - São Paulo (SP), Brasil.

1 Acadêmica do Curso de Enfermagem, Universidade Federal de São Paulo - UNIFESP - São Paulo (SP), Brasil.

${ }^{2}$ Professora Adjunto, Escola Paulista de Enfermagem, Universidade Federal de São Paulo - UNIFESP - São Paulo (SP), Brasil. 


\section{INTRODUÇÃO}

Ter um filho com câncer pode contribuir para desestruturar a base familiar, pois gera sofrimento em todas as pessoas envolvidas. Diversos estudos vem sendo realizados a fim de ampliar o conhecimento sobre o enfrentamento da doença e do tratamento para a unidade familiar e para subgrupos, específicos como pais, irmãos e a própria criança doente, com o objetivo de oferecer elementos que direcionem a prática clinica do enfermeiro, considerando que esse profissional tem o dever moral e a responsabilidade de cuidar não apenas da criança doente, mas, de todos os membros da família ${ }^{(1-3)}$.

Família pode ser definida como as composições de laços sanguíneos, as relações não formalizadas por parentesco, a família conjugal e extensa, o núcleo doméstico e a família não legitimada juridicamente, dentre outras possibilidades. Mas, não existindo acordo sobre a definição de família e sabendo, que é uma expressão não passível de conceituação, mas, só de descrição ${ }^{(4)}$, neste estudo consideramos a definição: "família é quem a pessoa considera que seja"(5).

Autores de estudos realizados sobre as repercussões do câncer na família ${ }^{(6-7)}$ revelam que o cotidiano familiar volta-se para a doença da criança e há mudança na função desempenhada pelos pais nos cuidados com ela. Assim, quando existem outros filhos, os pais nem sempre podem dar a atenção que eles necessitam ou desejam receber. O irmão sadio precisa, então, adaptar-se às circunstâncias que envolvem a criança com câncer, sendo cuidado muitas vezes por outros familiares e, algumas vezes, tendo seu papel dentro da família modificado.

A família permanece mais tempo com a criança doente, pois considera que ela precisa de maior atenção. Como consequência, os irmãos sadios podem se sentir negligenciados, tendo de lidar com as mudanças e suas emoções, sem o apoio que necessitam dos pais. Estes, por sua vez, esperam uma atitude normal do filho sadio, mesmo diante do processo de doença do irmão ${ }^{(6-8)}$.

Desta forma, o irmão sadio vivencia uma série de transformações em sua vida, assumindo novas tarefas, tanto domésticas como no cuidado com a criança com câncer. Os conceitos que os irmãos saudáveis criam da doença e do tratamento são construídos por meio das informações dos pais e das conversas que ouvem, o que pode muitas vezes gerar dúvidas, medos e temores que propiciam o surgimento de fantasias e reações somáticas ${ }^{(8)}$. Ao mesmo tempo em que compreende as necessidades do irmão doente, sente-se enciumado e abandonado ${ }^{(8-9)}$. No entanto, mantém-se firme ao lado do irmão doente e protege-o na escola e em seu meio social.

Os pais também tentam poupá-lo do sofrimento, sobretudo quando é inevitável a morte da criança com câncer, a fim de que tenham uma boa lembrança do irmão ${ }^{(10)}$.
A literatura apresenta estudos que avançam no conhecimento dessa situação, na perspectiva da família, da criança doente e dos irmãos sadios. Em nosso meio, ainda estamos iniciando nesse sentido, daí considerarmos necessário investir em estudos que nos ajudem a aprofundar a compreensão dessa experiência, a fim de fundamentar as ações do enfermeiro para cuidar dessas crianças. Desta forma, o objetivo deste estudo foi compreender, o significado da experiência de ter um irmão com câncer na perspectiva do irmão sadio.

\section{MÉTODOS}

Trata-se de um estudo exploratório descritivo, de abordagem qualitativa. A Análise de Conteúdo ${ }^{(11)}$ foi o referencial metodológico que permitiu compreender o significado da experiência de ter um irmão com câncer.

O estudo foi realizado em uma instituição filantrópica de assistência à criança com câncer, vinculada a uma universidade pública no Município de São Paulo.

Participaram cinco irmãos sadios de crianças em fase de pós-tratamento de câncer, com idade superior a 12 anos, considerando-se que estão ou passaram pela fase das operações formais ${ }^{(12)}$. O número de sujeitos foi definido no decorrer da coleta e análise dos dados, pela saturação das categorias analíticas.

O projeto de pesquisa foi aprovado pelo Comitê de Ética em Pesquisa da Instituição, após autorização da Gerência de Enfermagem do local onde foi realizado o estudo. Em primeiro lugar, contatava-se a criança com câncer pós-tratamento e seu acompanhante, indagando se consentiam que o irmão(ã) falasse a respeito da experiência sobre a doença. Havendo concordância dos pais e das crianças com câncer, estes assinavam o Termo de Consentimento Livre e Esclarecido e agendávamos a entrevista com o irmão sadio em local apropriado.

Entrevistas individuais semiestruturadas foram realizadas com cinco irmãos sadios de crianças com câncer em fase de cura, no período de março a abril/2008. Durante cada entrevista, foram explorados os seguintes tópicos:

- A vivência do diagnóstico de câncer;

- A vivência no período do tratamento e na fase póstratamento;

- As modificações na dinâmica familiar;

- Os pensamentos, sentimentos e ações desencadeados pela experiência de doença; e

- O enfrentamento nos momentos considerados mais difíceis.

Todas as entrevistas foram gravadas em mídia digital e transcritas integralmente pelos pesquisadores.

A seguir, nos dados do Quadro 1, apresenta-se a caracterização dos irmãos saudáveis participantes da pesquisa:

Os dados coletados na entrevista foram analisados 
seguindo os passos da Análise de Conteúdo ${ }^{(11)}$. Trata-se de um processo de identificação, codificação e categorização dos padrões primários nos dados, .

\section{RESULTADOS}

A análise dos dados permitiu identificar o tema tornando-se amadurecido com o sofrimento, que representa o significado da experiência do irmão sadio da criança com câncer durante as fases do diagnóstico, tratamento e cura.

O irmão sadio vivencia uma situação de muito sofrimento, pois é testemunha da dor simultânea dos pais e da criança doente, assim como sua própria angústia com tudo o que está acontecendo. Neste contexto de sofrimento, ele busca participar do tratamento, procurando apoiar e buscar apoio da família, amigos e da religião, para assim dar força e ajudar à criança doente. Sente-se aliviado ao receber o diagnóstico de cura da criança, porém permanece receoso de que algo possa voltar a acontecer com ela, como a recidiva da doença. Tem conhecimento da importância da consulta de rotina e acompanha-a, quando há oportunidade, sempre com esperança de cura definitivamente.

Nesse contexto de intenso sofrimento, o irmão sadio torna-se mais amadurecido, tendo de lidar ainda na infância ou na adolescência com um ente querido que enfrenta uma situação de doença, com a possibilidade de morte, pois apresenta muitas vezes recaídas durante o tratamento. Desta forma, o irmão sadio passa a valorizar de modo mais acentuado a convivência familiar e os pequenos atos do cotidiano que, anteriormente, passavam despercebidos.

Este tema possui cinco subtemas, compostos por categorias, apresentados a seguir:

\section{A descoberta da doença}

O irmão sadio começa a perceber que algo errado está acontecendo em sua família, pois, de repente, todos estão mais preocupados com a saúde de seu irmão. Observa a preocupação dos pais e parentes mais próximos ao surgirem sinais e sintomas no corpo da criança que consideram suspeitos. Nota que os pais mobilizam-se, recorrendo aos profissionais para consultas e exames. Quando têm recursos, utilizam o convênio de saúde, quando não, recorrem à rede hospitalar que lhes é disponibilizada.

Os pais, ao se reunirem para conversar, revelam-lhe o diagnóstico de câncer do irmão. Isto o faz descobrir que seu irmão apresenta uma doença que imagina ser muito grave, pois mobiliza a todos. Sofre com o diagnóstico, pois não tinha conhecimento sobre a doença nem sabia o que era câncer, daí acreditar que a cura seria simples. Com o passar do tempo, ao vivenciar as dificuldades provocadas, descobre que se trata de uma doença difícil e dolorosa para todos.

"Eu fiquei sabendo por intermédio do meu pai, depois de uma semana que eles tinham tido o resultado do exame... a gente sentou para conversar e explicon a situação, procurou esclarecer o que era no caso." (E1)

"É, bem estranho assim, é... um baque na hora não tem como não ser. Foi muito complicado, uma vez que você não está esperando e eu me senti muito mal. Não esperava isso um dia ...no começo foi difícil, é câncer não tem como você não pensar nisso. Fica pensando... sabe que a chance de uma cura é difícil ..." (E5)

\section{A participação no tratamento da criança com} câncer

Com a descoberta do diagnóstico da criança, no caso de irmão sadio adolescente ou adulto jovem, ele busca participar do tratamento, lendo e pesquisando sobre o câncer para melhor se preparar e poder ajudar, tanto seu irmão como sua família. Torce para que a situação resolva-se rápida e facilmente e fica na expectativa de que os exames revelem a possibilidade de cura, cuja chance acredita ser relativamente alta.

“... comecei a ir atrás das coisas, comecei pesquisar mais, o caso dela eu pesquisei muito assim, fui atrás de ler pra ler, o que eram as coisas e fiquei me sentindo melhor, e eu vi que o caso de oportunidade de cura era relativamente alta para câncer, mas é difícil porque ... fica com aquele fantasma o tempo todo que alguém que você gosta pode morrer" (E5)

Assim, ele procura apoio da família e dos amigos para se sentir melhor e poder dar força ao irmão doente. Observa que a família recebe o apoio de muitas pessoas nesta fase, até mesmo de quem conhece somente após a doença e há a reaproximação de alguns amigos. Busca ainda apoio espiritual, que lhe dá conforto.

Quadro 1 - Caracterização dos sujeitos da pesquisa

\begin{tabular}{|l|c|c|c|c|c|}
\hline Iden tificação do irmão s adio & E1 & E2 & E3 & E4 & E5 \\
\hline Sexo & Ma sculino & Fem inino & Feminino & Feminino & Masculino \\
\hline $\begin{array}{l}\text { Idade no momento do diagn óstico de } \\
\text { cân cer da cria nça }\end{array}$ & 20 an os & 8 an os & 3 anos & 13 anos & 21 an os \\
\hline Idade no momento da ent re vista & 23 an os & 12 anos & 18 anos & 17 anos & 25 an os \\
\hline Diagnóstico da crianç doente & Tumor ósseo & Tumor de Wilms & Tumor de Wilms & Linfoma & Lin foma Hodgkins \\
\hline Núme ro de irmãos & 3 & 1 & 2 & 2 & 1 \\
\hline
\end{tabular}


Por perceber o sofrimento da criança doente, o irmão procura mostrar-se presente em todos os momentos, mesmo quando ela está internada. Manda cartas, telefona, vai visitá-la no hospital, demonstrando seu apoio. Também envolve os amigos para manterem contato, a fim de estimular a criança e nota que ela se alegra com isso. Tenta ser um porto seguro, ajudandoa, especialmente, quando ela pensa que morrerá.

“... en ficava escrevendo cartinha e pedia para o men pai, minha mãe dar pra ela. Ai fiz as coleguinhas dela escreverem cartas e ai a gente fez várias cartinhas, desenhos e escreveu várias coisas para estimular ela, ficava feliz de a gente ficar pensando nela, falava por telefone e mandava pra ela as cartas, pedia pro meu pai ou minha mãe entregar..." (E4)

O irmão participa dos cuidados para proteção da criança. Evita contar que ela tem câncer, a fim de poupála de situações que considera desagradáveis e constrangedoras. Pensa que o mais importante é não a preocupar e não a deixar se abater. Acredita que o melhor é não mudar a maneira de tratá-la, mantendo firmeza em suas atitudes, cobrando resultados escolares, a fim de não a superproteger. Opõe-se quando as pessoas tratam-na com excesso de zelo, porque acredita que isso faz com que a criança pense que a situação de sua saúde é muito delicada. Pede ajuda aos amigos quando julga necessário, procura seguir com rigor todas as orientações da equipe médica, sobretudo aquelas relacionadas aos cuidados com o ambiente, a alimentação e higiene doméstica, a fim de evitar expô-la a infecções e complicações.

"Levava sempre na nutricionista e via bem a alimentação, evitava bastante coisas da rua, comida assim, de fora... de lanchonete, a gente não sabia como era feito, mas ela sempre gostou de comer... A gente fazia na nossa casa, Lavava bem as verduras, frutas. Dava bastante chicória pra ela, dava suco de beterraba com cenoura. Nossa! Isto ai ela odiava quando a gente fazia. Às vezes, batia o ovo, colocava o leite e dava pra ela, ficava passando mal, mas era... ai quando ela fezo transplante, então, ai a limpeza era total e geral, assim, era a casa inteira tinha ... limpava canto por canto, passava álcool. Nossa! Era tudo, era a mão, era garfo, talhares e pratos que eram separados, o copo que ela bebia era separado.” (E4)

Mas, quando se trata de irmão que viveu essa experiência muito cedo, ainda na fase pré-escolar, escolar e puberdade, nem sempre esse movimento ocorre, até porque nesse momento ele não consegue compreender, o que está acontecendo com seu irmão nem com seus pais. Ao narrar sua experiência, ele revela o quão difícil foi vivenciar o afastamento dos pais e do irmão com câncer.

Repercussões da doença na família

O irmão sadio percebe que o diagnóstico de câncer provoca inúmeras mudanças na família, limitando os encontros e a participação de todos juntos durante o tratamento, o que só é recompensado ao final com a cura e a reorganização familiar. Nota que a família percebe-se, a partir daí, capaz de superar todos os desafios. Compreende que a doença da criança traz repercussões psicológicas para todos os membros da família, pois sofrem e se mantêm apreensivos durante a doença, o que pode inclusive desencadear problemas de saúde. Percebe também que apesar de todos os problemas, a família sempre se mostra disposta a solucioná-los, e adapta-se à nova situação, aprendendo a lidar com o câncer ao aparecerem as dificuldades.

Percebe ainda que a situação de doença aproxima a família, deixando-a mais compreensiva. As oportunidades para ficarem juntos são mais aproveitadas, apesar das brigas com a criança, sente-se mais unido a ela. O irmão sente grande admiração pelo esforço dos pais que, apesar de todas as dificuldades e problemas financeiros, continuam trabalhando, acompanham a criança durante suas consultas no hospital e internação, não deixam de instruir seus filhos, evitando mostrar abatimento com a situação. $\mathrm{Na}$ verdade, para ele, os pais representam o único esteio da família.

"Eu sei que grande parte que eu poderia aproveitar junto com eles, é... foi perdida, entre aspas porque sei que minha mãe estava buscando beneficios para nossa família, que era a saúde de meu irmão. Mas assim muitas coisas que a gente poderiapassarjuntos foram desprezadas com o tempo, entendeu? Devido a este problema.” (E3)

"A familia está bem mais unida, bem mais compreensiva, meu pai então... melhorou assim uns $90 \%$, ele era super-rígido, superpai... aquele pai sabe? Que não podia fazer isto que ia sair do visto do pai, do estilo do pai, mas até tudo mudou bastante, depois de tudo, mas no momento de dificuldade e adaptação ao problema dela. Foi mais dificuldade, mas no instante a gente tira de letra." (E4)

\section{Repercussões da doença em sua vida pessoal}

$\mathrm{O}$ distanciamento familiar que ocorre durante o tratamento da criança e a necessidade de ficar sob os cuidados de outras pessoas é percebido pelo irmão, como uma das situações mais difíceis, pois não consegue estar com seus familiares e sente saudades. Em alguns casos, por não ter idade suficiente na época do diagnóstico e tratamento, recorda-se que era necessário entrar escondido na unidade de internação para ver a criança, pois a visita não era liberada. Durante esta fase, perdeu o interesse pelos estudos, faltava muito à escola e preocupava os professores pela sua tristeza.

"E quando ela ficou lá no hospital, não me deixavam ver ela, eu tinha que subir escondida pra ver ela. Ai eu subia rapidinho e voltava, ai não dava pra eu ver direito... não sei como que foi assim direito. Foi muito difícil ficar este tempo todo longe dela e da minha 
mãe. Que eu só podia ver minha mãe assim... eu não podia subir lá, ai en ficava lá embaixo, teve vezes, de en ficar lá embaixo sozinha, meu pai subia, ai en ficava lá com saudade da minha mãe. Minha mãe descia, ficava só um pouquinho e subia de novo, isso foi difícil, ficar longe delas..."'(E2)

O irmão sente-se triste ao perceber que a criança vivencia situações dolorosas, como os efeitos colaterais dos medicamentos e das cirurgias. Percebe a gravidade da doença, que se prolonga por mais tempo do que se espera e porque os médicos não dão esperança de cura. Fica triste por pensar na possibilidade de morte e evita o contato da criança com outras pessoas, dada sua baixa imunidade. Mesmo após a cura da criança, não gosta de se lembrar da época da doença, sendo difícil falar sobre o assunto. Prefere deixá-lo no esquecimento.

"Teve um dia que ela chegou a falar assim: ás vezes, eu acho que vou morrer, sabe? Ela falou para mim, e eu ainda lembro... en tava no banheiro, aí eu tava ajudando ela, porque ela não conseguia nem levantar, né? Ai ela comeģou a chorar e falou que achava que ia morrer...começou a chorar, foi bem triste, sabe?" (E4)

\section{Com esperança de cura definitiva}

Receber a indicação de possível cura faz que pense em um milagre que Deus realizou na vida de sua família. É grato ao acompanhamento que a criança recebeu no hospital e à atenção dispensada pelos profissionais da saúde. Sabe que é importante seguir a consulta de rotina e a acompanha sempre que pode nos exames para descobrir se há algum vestígio da doença. Mantém a esperança de que a criança seja curada definitivamente.

"Mas graças a Deus conforme o tempo, muitos exames... foram mostrando que não tinha nada, graças a Deus e que ela poderia estar curada definitivamente... teve que continuar tomando um par de cuidados... para não acontecer, né? De voltar a doença ainda mais forte, ela tava se tratando... mas foi ótimo, aliviou, sabe? Foi maravilhoso saber que ela tava curada e que agora é só acompanhamento. Se Deus quiser não vai ter mais nada." (E4)

Passa a valorizar de forma mais acentuada a vida, a família e até mesmo os pequenos atos cotidianos que até então eram despercebidos.

"Mudou porque a gente agora parece que é mais próximo do que a gente era antes. Você começa a dar valor pra pequenas coisas que, às vezes, passava despercebido, então, isto causa uma proximidade maior. Algumas coisas que você tinha antes e que você não dava valor. Exemplo bobo que, que nem eu odeio futebol, sempre fui um cara que odiou futebol, hoje em dia se ele me chama... eu vou jogar futebol junto!! Porque quero estar junto... é outra coisa, é diferente agora." (E1)

\section{DISCUSSÃO}

O irmão sadio sofre em todas as fases do câncer da criança, a começar pelo diagnóstico, marcante pelo impacto da descoberta da doença e desconhecimento de suas consequências. O sofrimento é grande, em razão de o câncer acometer uma pessoa tão querida e próxima, de difícil tratamento e reduzidas chances de cura.

O sofrimento vai se intensificando, conforme ele vive as experiências. No começo, pensava que era uma doença fácil de ser resolvida e, aos poucos, conforme percebe as marcas do tratamento, compreende que não é tão simples. Os irmãos mais novos revelam que sofrem ao se sentirem sozinhos nesta fase, sendo difícil suportar o distanciamento da família, e o fato de permanecerem sozinhos em casa ou serem cuidados por algum parente. Outro fator que os afligem, são as idas ao hospital, por não receberem permissão para ver a criança.

Ocorre a necessidade de reorganização dos papéis de todos na família, a fim de que a criança doente sinta-se bem em todos os locais, tanto em casa, como no hospital. As alterações na rotina dos irmãos sadios, que têm nessa circunstância de se tornar responsável pelo próprio cuidado também se revela fonte de sofrimento e promove seu amadurecimento. Em alguns casos, com a ausência da mãe, o irmão sadio é transferido para a casa de algum parente, o que lhe causa perdas e ganhos. Na literatura, esse aspecto vem sendo bastante discutido, e os autores propõem medidas para aliviar a situação. ${ }^{(13-14)}$

$\mathrm{O}$ sofrimento vivenciado repercute na escola. Os irmãos sadios revelam que têm dificuldade de concentração e faltam às aulas, em razão de preocuparse com a criança doente. Com tal conduta, deixam os professores consternados ao perceberem o quanto estão tristes com a doença do irmão. $\mathrm{Na}$ literatura ${ }^{(14)}$, tem sido descrito que os irmãos sadios da criança com câncer podem apresentar problemas de conduta escolar, problemas psicossomáticos, comportamento impulsivo hiperativo, além de outros distúrbios de comportamento.

Autores $^{(15-16)}$ reforçam que os enfermeiros devem incentivar os pais a dedicarem mais tempo aos filhos sadios, explicando-lhes sobre a doença e tratamento do câncer, a fim de minimizar seu sofrimento. É essencial que o enfermeiro planeje intervenções com a família, auxiliando-a no processo de enfrentamento e adaptação a este novo período. As informações são ofertadas pela enfermeira aos familiares deixando-os satisfeitos e conhecedores dos acontecimentos.

Para planejar o cuidado com o irmão sadio, é preciso considerar a fase de desenvolvimento em que se encontra, sua faixa etária, bem como avaliar suas atividades dentro da dinâmica familiar ${ }^{(13)}$.

Neste estudo, a experiência do irmão sadio revelouse plena de sofrimento e provoca seu amadurecimento. 
Os autores de um estudo ${ }^{(17)}$ observaram que, embora alguns irmãos experimentem resultados adversos, muitos deles parecem beneficiar-se emocional e psicologicamente da experiência do câncer. Os irmãos sadios relataram que a empatia, maturidade pessoal, coesão familiar, independência, compaixão pelo próximo e apreciação pela vida aumentaram, indicando que eles apresentam resiliência a essa situação.

\section{CONCLUSÃO}

Este estudo avançou ao revelar o processo de amadurecimento vivenciado pelo irmão sadio na convivência com um irmão doente com câncer. A importância da atenção que deve ser dispensada aos irmãos sadios da criança doente, em razão do desconhecimento da doença, do tratamento e de seus efeitos colaterais que desencadeiam muito sofrimento.

O presente estudo apresenta como limitações a

\section{REFERÊNCIAS}

1. Nascimento LC. Crianças com câncer: a vida das famílias em constante reconstrução [tese]. Ribeirão Preto: Escola de Enfermagem de Ribeirão Preto da Universidade de São Paulo; 2003.

2. Misko MD, Bousso RS. Manejando o câncer e suas intercorrências: a família decidindo pela busca ao atendimento de emergência para o filho. Rev Latinoam Enferm. 2007;15(1):48-54.

3. Nascimento LC, Rocha SM, Hayes VH, Lima RA. Crianças com câncer e suas famílias. Rev Esc Enferm USP. 2005;39(4):469-74.

4. Durman S, Piccoli M, Shneider JF, Stefanelli MC. Discursos de estudantes de enfermagem sobre familia. Acta Sci Health Sci. 2004;26(1):47-51.

5. Murray P. Influências da família na promoção da saúde da criança. In: Hockenberry MJ, editor. Wong fundamentos de enfermagem pediátrica. 7a ed. Rio de Janeiro: Elsevier; 2006. p. 30-54.

6. Oliveira AP. Buscando a cura: a experiência da família da criança que sobrevive ao câncer [dissertação]. São Paulo: Escola de Enfermagem da Universidade de São Paulo; 2002.

7. Alencar MP, Pereira AN, Pereira MC. Famílias com crianças com câncer. Salvador: CienteFico; 2004 [citado 2007 Ago 18 ]. Disponível em http://www.frb.br/ciente/Impressa/ Psi/2004.2/SAUDE_Alda.pdf

8. Pedrosa CM, Valle ER. Ser irmão de criança com câncer: estudo compreensivo. Pediatria (São Paulo). 2000;22(2):185-94. grande diferença de idade entre os sujeitos entrevistados, reduzido número de sujeitos e o tempo de sua realização. Porém os resultados permitem sugerir algumas ações, tais como mudança nas regras e rotinas da instituição, favorecendo a proximidade da família. Mas recomendar a inclusão dos irmãos sadios durante as internações da criança doente, garantindo-lhe acesso a informações pertinentes à sua idade. A manutenção de um diálogo aberto com os pais, a fim de ouvi-los e alertando-os para os problemas que os irmãos sadios enfrentam tais como a separação da família, que neste estudo foi apontado como um dos momentos mais difíceis na convivência com a doença. Assim como os problemas na escola e na socialização. Para tanto, é preciso sensibilizar e capacitar a equipe para cuidar da família como unidade, considerando as interações entre os membros e as repercussões que a doença provoca na dinâmica familiar, de forma a possibilitar que o sofrimento no qual são envolvidos seja amenizado.

9. Azeredo Z, Amado J, Silva HN, Marques IG, Mendes MVC. A família da criança oncológica: testemunhos. Acta Med Port. 2004;17(5):375-80.

10. Giovanola J. Sibling involvement at the end of life. J Pediatr Oncol Nurs. 2005;22(4):222-6.

11. Mayan MJ. An introduction to qualitative methods: a training module for students and professionals. Edmonton, Canada: Qualitative Institute Press; 2001

12. Bee H. Juntando tudo: a criança em desenvolvimento. In: Bee H. A criança em desenvolvimento. 7a ed. Porto Alegre: Artmed; 1996. p. 453-75.

13. Cavicchioli AC. Câncer infantil: as vivências dos irmãos saudáveis [dissertação]. Ribeirão Preto: Escola de Enfermagem de Ribeirão Preto da Universidade de São Paulo; 2005.

14. Woodgate RL. Siblings' experiences with childhood cancer: a different way of being in the family. Cancer Nurs. 2006;29(5):406-14.

15. Ortiz MC, Lima RA. Experiences of families with children and adolescents after completing a cancer treatment: support for the nursing care. Rev Latinoam Enferm. 2007;15(3):411-7.

16. Souza MF, Barros AL, Matheus MC. Agregar valores. Acta Paul Enferm. 2005;18(3):5-5.

17. Hold-Heerschop C. Commentary on "Experience of siblings of children treated for cancer". Eur J Oncol Nurs. 2007;11(2):113-4. 